\title{
MUJERES, MASONERÍA Y REVOLUCIÓN EN FILIPINAS $(1896-1897)^{1}$
}

\author{
BEATRIZ VitAR \\ UNIVERSIDAD DE CÁDIZ
}

\section{RESUMEN}

En este trabajo se analiza el proceso de instauración de la masonería en Filipinas y la acción conspirativa desarrollada por las mujeres mestizas a través de las cámaras de adopción creadas a fines del siglo XIX. Las logias femeninas se formaron por iniciativa de los líderes ilustrados nacionalistas, también del grupo mestizo, y cumplieron un importante papel en la revolución de 1896, apoyando las actividades conspirativas de la sociedad secreta y revolucionaria Katipunan, creada con el fin de luchar por la independencia de las Islas.

Palabras clave: Mujeres, Masonería, Revolución, Filipinas, Siglo XIX.

\section{ABSTRACT}

The paper's focus on Filipino Nationalism, the Masonry process and revolutionary activities of half-caste class women within the Masonic lodges founded in the $19^{\text {th }}$ century, as well as the role of this female associations -known in Masonic History as adoption's chambers- through their collaboration with Katipunan society, which headed the Revolution against Spain.

Keywords: Women, Masonry, Revolution, Philippines, $19^{\text {th }}$ century.

\footnotetext{
Una primera aproximación al tema en: VITAR, Beatriz, "La participación femenina en la insurrección filipina de 1896. El caso de la logia Semilla y la trayectoria de Rosario Villarruel", en El conflicto de 1898. Antecedentes y consecuencias inmediatas (E. Burgos Malavé, ed.), S. J. de Puerto Rico, Universidad de Puerto Rico, 2000, p. 455-472.
} 


\section{INTRODUCCIÓN}

Mediante estas páginas ofrecemos un panorama sucinto acerca del papel de las mujeres de Filipinas en el proceso revolucionario de finales del siglo XIX, analizando el germen y desarrollo de las ideas nacionalistas hasta desembocar en la insurrección de 1896, que contó con una activa participación femenina. A estos efectos, es preciso presentar en primer lugar el proceso de instauración de logias en el Archipiélago y las causas que lo hicieron posible, en tanto que fenómeno estrechamente ligado a la masonería peninsular y, en especial, a los ideales nacionalistas filipinos. Asimismo, abordaremos las particularidades de las logias femeninas o cámaras de adopción y su intervención en la lucha independentista, mediante una acción coordinada con la sociedad revolucionaria Katipunan.

En primer lugar, cabe señalar que, desde el punto de vista teórico, el estudio sobre la presencia femenina en la masonería del siglo XIX, impone la incorporación de otras perspectivas de análisis, apuntando al papel social adjudicado a las mujeres y a una imagen estereotipada de éstas, creada en función de los ideales masculinos; en tal sentido, resulta de gran interés, como marco de referencia general, el reciente estudio de Natividad Ortiz Albear ${ }^{2}$. En el caso particular que nos ocupa, las principales dificultades que se encuentran para su estudio son las fuentes ${ }^{3} \mathrm{y}$ los escasos estudios específicos sobre este tema en el ámbito filipino. En la documentación del siglo XIX y en alguna bibliografía, las referencias a estas cuestiones son muy escuetas, cuando no cargadas de estereotipos y condicionamientos de género. A ello debe sumarse el prejuicio étnico, que envolvía por igual a los hombres y mujeres de la lucha independentista, teniendo en cuenta que el liderazgo fue ejercido en su mayoría por mestizos, gente de una raza inferior o degradada en la concepción del pensamiento regeneracionist $a^{4}$. A la par de este desprecio, la militancia revolucionaria de hombres y mujeres de este grupo fue puesta en ridículo o minusvalorada mediante el uso de términos que aludían a una travesura $a^{5}$, cual si de niños se tratase, quedando así también encasillados en una condición de minoridad que deslegitimaba sus luchas y reivindicaciones.

Por otra parte, hay que destacar que todo lo relacionado con la masonería estuvo impregnado de mitos y leyendas, dado su carácter secreto. De este modo, es importante analizar cuándo y cómo se habla de las masonas, ya que en las raras ocasiones en que se hace mención a su trayectoria aparecen doblemente demonizadas, en su condición de mujeres y de separatistas fanáticas. Sin ánimo de someter los testimonios decimonónicos sobre las revolucionarias filipinas a un análisis de género, es importante señalar, en tanto ello repercute en la disponibilidad de información, que esos rasgos del discurso no son sólo achacables a los miembros o ex funcionarios de la administración colonial sino también, en ocasiones, a los hombres del propio grupo revolucionario, como es el caso del destacado líder independentista Apolinario Mabini ${ }^{6}$, cuyo relato carece de referencias a la presencia e importancia de la acción femenina en los mismos.

\footnotetext{
ORTIZ ALBEAR, Natividad, Las mujeres en la masonería, Málaga, Servicio de Publicaciones de la Universidad de Málaga, 2005. Colección Atenea, 49.

3 En general los testimonios consisten en relatos de testigos de los acontecimientos, ya sea miembros de la administración colonial o políticos de diversas tendencias (algunos de ellos masones) y comentarios de prensa de diferente extracto ideológico, a excepción de Las Dominicales del Libre Pensamiento (Madrid), publicación semanal destacada por su reivindicación de la mujer.

4 Véase al respecto CASAÚS ARZÚ, Marta E., "Las redes intelectuales centroamericanas y sus imaginarios de nación (1890-1945)", en Circunstancia (Revista de Ciencias Sociales del Instituto Interuniversitario de Investigación Ortega y Gasset), Vol. III (enero 2006), nº 9. Revista Electrónica Cuatrimestral.

5 Los líderes nacionalistas eran mestizos de español-filipino y también mestizos de chino-filipino, como era el caso de José Rizal. En ciertos escritos de prensa y de autores opuestos a la masonería, priman las alusiones despreciativas a los protagonistas de la conspiraciones filipinas, a quienes se tildaba de mesticillo travieso" o "astuto", por citar algunos ejemplos.

6 MABINI, Apolinario, Memorias de la Revolución Filipina, Manila, Departamento de Educación, 1960.
} 
A través de estas páginas esbozaremos los alcances de la participación de las mujeres en las logias y en la insurrección de 1896, cuyo primer antecedente se encuentra en un taller masónico establecido en Hong Kong, activo centro de propaganda separatista. En los años previos a la primera intentona independentista, las masonas filipinas intensificaron su actividad conspirativa, pasando de las logias a una intervención directa en la sociedad secreta Katipunan, principal motor de aquel movimiento.

\section{LA MASONERÍA EN FILIPINAS}

Para entender el fenómeno de expansión de las logias en el Archipiélago, y en especial las vías por las cuales algunas mujeres filipinas -valgan como ejemplo los casos de Rosario Villarruel, Marina Dizón o de las hermanas Rizal- llegaron a formar parte de las sociedades secretas que laboraron por la independencia, es necesario remontarse a la revolución española de 1868, un suceso crucial para la difusión de las teorías democráticas y de la masonería, tanto en la Península como en sus posesiones ultramarinas. Los liberales y republicanos españoles afiliados a las logias alentaron las demandas de los sectores ilustrados filipinos, cuyas personalidades más destacadas encararon, en una primera etapa, la lucha por las libertades y por el derecho a la representación de Filipinas en las Cortes, recuperando así el carácter de provincia española perdido en $1837^{7}$.

En una primera fase del desarrollo masónico en Filipinas -que arranca a mediados del s. XIX-, las logias estuvieron integradas exclusivamente por peninsulares ${ }^{\mathbf{8}}$, debiéndose su introducción a la necesidad de hacer frente a las influencias de la masonería extranjera, expandida en Singapur, Hong Kong, Java, Macao y los puertos de China9. A partir de la creación de la primera logia en Manila, en 1850, se fundaron sociedades masónicas en diversas ciudades del Archipiélago, como Iloilo y Cebú (Islas Visayas), puntos estratégicos donde acechaban las potencias enemigas de España (Vergara 1896: 20).

Décadas antes de la revolución de 1896, ya se habían producido reacciones contra la situación de privilegio y el férreo dominio de las órdenes religiosas que evangelizaron la colonia -la frailocracia tan criticada por los nacionalistas filipinos- como la rebelión de Cavite de 1872, que se saldó con la ejecución de dos sacerdotes nativos. La exacerbación de los sentimientos nacionalistas y las consiguientes deportaciones tras este suceso, fueron aprovechadas por las logias masónicas de Hong Kong (tanto alemanas como inglesas), que dieron su acogida a los filipinos perseguidos por su implicación en aquella rebelión (Vergara 1896: 15). Se formó así un importante núcleo para la difusión de las ideas separatistas, al que se sumaron las mujeres e hijas de los emigrados. Sus tareas se vieron favorecidas por las libertades de que disfrutaban en aquella colonia de Inglaterra, nación que por todos los medios buscó quebrar el poder español en la zona. A través de libros y de diverso material impreso introducido en su país de origen, los filipinos afincados en el exterior lograron difundir los ideales nacionalistas en contra de la opresión del imperio teocrático en el Archipiélago, rodeado de países donde constituyen atmósfera social la libertad de imprenta, la libertad de asociación, libertad de conciencia, inviolabilidad de

7 ORTIZ DE ANDRÉS, María Asunción, Masonería y democracia en el siglo XIX: el Gran Oriente Español y su proyección político social (1888-1896), Madrid, Universidad Pontificia de Comillas, 1993, p. 233-235.

8 La primera logia se llamó Primera Luz Filipina y fue su fundador José Malcampo y Monge (VERGARA, Francisco E., La masonería en Filipinas, París, 1896, p. 31).

9 CABRERO, Leoncio, "La actitud de la masonería ante la independencia de Filipinas", en Masonería Española y América (J. Ferrer Benimeli, comp.), Zaragoza, tomo II (1993), p. 1098. 
domicilio, etc.$^{10}$. La actividad de los filipinos en Hong Kong y en ciudades de Europa -especialmente Madrid-, sería trascendental para la preparación del primer movimiento revolucionario en el Archipiélago (1896), en el que no se hizo más que obedecer ciegamente, según la prensa conservadora de la época, las consignas dictadas desde esos centros de conspiración ${ }^{11}$.

En lo que respecta a la masonería española, el Gran Oriente Español (GOE), dirigido por Miguel Morayta, y el Gran Oriente Nacional de España (GONE), liderado por Pantoja, brindarían a los nacionalistas filipinos la cobertura necesaria y también la estructura organizativa para intensificar su campaña reformista. La primera logia de filipinos establecida en Madrid fue Solidaridad (1886), a la que siguió el establecimiento de la delegación del Comité de Propaganda $^{12}$ (fundado en las Islas en 1888) y de la Asociación Hispano Filipina (1889) ${ }^{13}$, siendo su órgano de prensa la revista quincenal La Solidaridad. Los estudiantes filipinos residentes en Barcelona y Madrid (Marcelo H. del Pilar, José Rizal, Mariano Ponce, etc.), buscaron el apoyo de la masonería para su programa de reformas, logrando la flexibilización de los Estatutos del GOE a fin de que participaran indígenas y mestizos en las logias del Archipiélago. Como consecuencia de ello, la organización de Morayta contó en las Islas con logias bajo su obediencia a partir del establecimiento, en enero de 1891, de la logia madre Nilad, la primera sociedad masónica integrada exclusivamente por filipinos (Ortiz de Andrés 1993: 303). Tras este acontecimiento, la masonería se expandió no sólo en el Archipiélago ${ }^{14}$ sino también en Hong Kong, mediante la creación de talleres o Triángulos que más tarde se transformaron en logias. De mayo a junio de 1892 se incrementó de modo notorio el número de sociedades secretas en Filipinas ${ }^{15}$, compuestas por los filipinos ilustrados, que hallaron en ellas el ámbito idóneo para discutir la actualidad política de la colonia -y de otras posesiones españolas en Ultramar- así como para estar al tanto de las nuevas corrientes de pensamiento (Ortiz de Andrés 1993: 304-305).

En junio de 1892, tras su regreso a Manila, José Rizal convocó en el barrio de Tondo una reunión de filipinos, entre los que se destacaban "hombres de carrera y comerciantes, industriales y

10 Las Dominicales del Libre Pensamiento, $\mathrm{n}^{\circ}$ 657. Madrid, 15 de marzo de 1895, p. 2 (Biblioteca Nacional, Madrid). Este periódico se difundía en Manila, aunque tras los sucesos de 1896 y considerando su posición ideológica, las autoridades coloniales solicitaron se prohibiese su circulación en las Islas. Esta y otras informaciones que citaremos más adelante fueron extraídas de una publicación de la época, que recoge distinta documentación gubernamental y artículos relacionados con la conspiración de 1896: La Política de España en Filipinas [dirigida por W. E. Retana], 1897, Madrid, Impr. Minuesa de los Ríos, p. 11 [V. "La insurrección”. Telegramas oficiales. 15 de febrero de 1897].

11 "La instrucción pública" (2 de septiembre de 1897), en La Situación del País (Colección de artículos publicados por La Voz Española acerca de la insurrección tagala, sus causas y principales cuestiones que afectan a Filipinas), Manila, 1897, p. 150.

12 El plan de acción de este Comité, que llevaba como lema la lucha contra la opresión y la tiranía, comprendía dos fases, una de educación y la otra de propaganda activa, buscando para esta última el apoyo de la masonería peninsular a través del GOE.

13 VITAR, Beatriz, "La Asociación Hispano Filipina de Madrid. Sus relaciones con la masonería y su incidencia en el movimiento independentista filipino", El Caribe y América Latina. El 98 en la coyuntura imperial, Morelia, Michoacán, Universidad Michoacana de S. Nicolás de Hidalgo, tomo II (1999), p. 39-51.

14 El apoyo de los masones peninsulares a las logias filipinas tendía a frenar el avance de las logias extranjeras, ya que de hecho existían algunas "del elemento inglés, de los filipinos inglesados [sic]" (VERGARA 1896: 28).

15 Esta expansión se vio favorecida por la legislación penal, que imponía penas leves a las asociaciones ilícitas y a los delitos de conspiración ("El Código Penal", de 30 de julio de 1897, en La Situación del País. Colección de artículos...), 1897, p. 105. Fue tal el crecimiento de la masonería que, en 1896, año de la primera revolución separatista, existía un total de "186 logias tagalas" (RETANA, Wenceslao E., Archivo del bibliófilo filipino: recopilación de documentos históricos, científicos, literarios y políticos y estudios bibliográficos, Madrid, tomo IV (1898), p. 292. 
propietarios de los más acaudalados"16, a los efectos de constituir la Liga Filipina. Esta organización nació para fortalecer los lazos solidarios entre los filipinos y luchar por medios pacíficos para conseguir una serie de reformas para las Islas, principalmente la igualdad de derechos con el resto de las provincias españolas ${ }^{17}$. Al mes siguiente se constituyó la sociedad Katipunan, de carácter secreto y revolucionario, con una base popular amplia y liderada por figuras con firmes ideales nacionalistas $^{18}$. En su plan conspirativo, esta organización contó con el apoyo de las logias y sus cámaras de adopción, que le sirvieron de tapadera ${ }^{19}$.

Los intelectuales filipinos de origen mestizo que sustentaron ideológicamente el movimiento independentista, constituían una minoría de universitarios con una holgada posición económica y posibilidad de cursar estudios en el extranjero (como fue el caso de José Rizal, Marcelo H. del Pilar y muchos otros), impregnándose así de las ideas más avanzadas en política y religión, mediante sus relaciones con las corrientes librepensadoras, el republicanismo y la masonería europea (España, Alemania, Francia e Inglaterra). En la Península, los hijos de la clase ilustrada de Filipinas, habían frecuentado la Universidad, el Ateneo, el Parlamento y los círculos republicanos ${ }^{20}$, apoyando a éstos y al Gran Oriente de España en sus programas, con el fin de recuperar la representatividad de Filipinas en las Cortes ${ }^{21}$, entre otras reformas. A su vez, en las Islas, las logias autóctonas aglutinaron especialmente a los mestizos chinos más ricos del país $^{22}$, recelosos de los peninsulares por su trato discriminatorio hacia los chinos (Cabrero 1993: 1098).

\section{LA MUJER FILIPINA EN LAS POSTRIMERÍAS DE LA COLONIA}

Una buena fuente para el estudio de la mentalidad femenina en el período prerrevolucionario son los diversos escritos de Rizal, en especial su novela Noli me tangere (1887), así como una de las cartas que enviara desde Alemania (en 11 de marzo de 1886) a su hermana Trinidad, a la sazón en Hong Kong ${ }^{23}$. En esa misiva, Rizal comparaba a las jóvenes germanas con sus congéneres filipinas, cuyas condiciones de vida distaban mucho de las de aquéllas, al estar sometidas a las opresivas normas de la sociedad colonial. Sobre las alemanas, nombraba cualidades tales como la seriedad, el estudio y la aplicación, remarcando el hecho de que no se cuidan mucho de los vestidos, ni de las joyas, pues se ocupaban más del fondo que de las apariencias; no ocultaba Rizal su admiración por esa autonomía y libertad de movimientos,

16 SASTRÓN, Manuel, La insurrección filipina y la guerra hispano-norteamericana en el Archipiélago, Madrid, 1901 , p. 49.

17 SCHUMACHER, John N. (S. J.), The Propaganda Movement: 1880-1895. The creators of a Filipino consciousness, the makers of Revolution, Manila, Solidaridad Publishing House, 1973. Fruto de las actuaciones de la Liga, junto con otras organizaciones filipinas en España, fue la sanción de la Ley de Reforma Municipal de Maura (1893), favorable a la autonomía municipal.

18 Muchos miembros del Consejo Regional Filipino del GOE también formaron parte de la sociedad Katipunan (MAURICIO, La gran traición, Barcelona, 1899, Imprenta de Miguel Borrás, p. 84).

19 CASTILLO Y JIMÉNEZ, José M. del, El filibusterismo en Filipinas, Madrid, Imprenta del Asilo de Huérfanos, 1897 , p. 376.

20 “Las causas de la insurrección” (12 de junio de 1897), en La Situación del País (Colección de artículos...), 1897, p. 24.

21 Este objetivo no llegó a lograrse, a pesar del apoyo de sectores liberales y republicanos, provocando a la larga la radicalización de los líderes nacionalistas, enrolados posteriormente en la sociedad Katipunan. Un columnista de la época había anticipado los efectos de este fracaso en las consecución de las reformas, sosteniendo que "la falta de representación parlamentaria de las Islas Filipinas es una amenaza a la integridad española" (Las Dominicales del Libre Pensamiento, $\mathrm{n}^{\circ}$ 657. Madrid, 15 de marzo de 1895, p. 2. Biblioteca Nacional, Madrid)

22 REVERTER DELMÁS, Emilio, La insurrección de Filipinas en 1896 y 1897, Barcelona, Centro Editor de A. Martín, 1899, p. 39.

23 "Epistolario Rizalino", en Documentos de la Biblioteca Nacional de Filipinas, compilados y publicados bajo la dirección de T. M. Kalaw, Manila, Bureau of Printing, 1930, tomo I (1877-1887), p. 171-172. 
que se manifestaba andando tan ligero o más que los hombres, llevando su libro, su cesta, sin hacer caso de nadie y sólo van a su obligación ${ }^{24}$. Imbuido de las ideas librepensadoras que fomentaron la preparación intelectual femenina en Europa, se comprenden las lamentaciones de Rizal acerca de que en Filipinas el adorno principal de todas las mujeres consista casi siempre en el vestido y en el lujo ${ }^{25}$ y no en la instrucción, aconsejando por ello a su hermana que estudiara, leyendo y leyendo con atención. A pesar de que a la postre habría de salir a relucir el tópico, rescatando Rizal la delicadeza de corazón de las filipinas en medio del clima represivo en que se desenvolvían sus vidas, es probable que sus observaciones hubiesen hecho mella y se difundiesen en el entorno que rodeaba a su hermana Trinidad, miembro de un Triángulo masónico en Hong Kong junto a otras jóvenes filipinas. El testimonio de Rizal es también de gran valor, si consideramos que muchos masones reivindicaban la instrucción de la mujer como vía para su liberación y para lograr el progreso de la sociedad ${ }^{26}$, sacudiéndose el yugo de la opresión, ejercida principalmente por el catolicismo. En España la masonería defendió el derecho a la educación de la mujer y la igualdad profesional con el hombre ${ }^{27}$. Las mujeres librepensadoras proclamaron incesantemente la necesidad de profundizar su formación, porque la mujer ignorante y supersticiosa no realiza ni puede realizar sus fines humanos; tal instrucción era inherente a su futura condición de madres, ya que era la garantía para dirigir a sus hijos por el sendero de la razón ${ }^{28}$.

En Filipinas, las mujeres mestizas pertenecientes a familias pudientes tuvieron acceso a la escuela primaria y secundaria, especializándose generalmente en la carrera de Magisterio. La educación constituía un feudo de las órdenes religiosas, como era el caso de la Escuela Normal Superior de Maestros de Manila -donde estudiaron muchas maestras y maestros que participaron en la insurrección filipina-, en manos de los jesuitas. Éstos, designados por un hermano masón en su discurso como afiliados a la Sociedad de San Ignacio de Loyola, fueron responsabilizados de haber degradado a la mujer, situándola muy lejos del puesto que le había conferido el cristianismo más primitivo, que sentó a la esposa en el mismo trono que al esposo (Álvarez Lázaro 1997: 303-304).

Aunque es de suponer que se ejercía un estricto control en las instituciones de enseñanza, las ideas nacionalistas habían ganado adeptas entre muchas maestras de enseñanza primaria, que se convirtieron en miembros de las sociedades secretas, tanto en Manila como en otras provincias, para luchar por las ideas independentistas. Sus movimientos alertaron a los servicios secretos de vigilancia, que iniciaron un seguimiento de los mismos, en la sospecha de que las maestras y maestros de instrucción primaria de los arrabales ${ }^{29}$ y pueblos de Manila y los de muchas provincias de Luzón y Visayas están afiliados a sectas masónicas ${ }^{30}$. Meses después del levantamiento,

Ibid., p. 171.

25 Desde otro extremo ideológico, se cargaban mucho más las tintas en lo que atañe al lujo en la mujer, advirtiendo que "inspira comercios escandalosos" (La Situación del País, Colección de artículos... "El Código Penal”, 30 de julio de 1897), 1897, p. 105.

26 ALVAREZ LÁZARO, Pedro F., La masonería, escuela de formación del ciudadano, Madrid, Universidad Pontificia de Madrid, 1997, p. 304-305.

27 MORALES RUIZ, Juan J., "La mujer en la masonería menorquina del siglo XIX”, en Masonería, revolución y reacción [IV Simposium Internacional de Historia de la Masonería Española. Alicante, 27-30 de septiembre de 1989], Alicante, Instituto de Cultura "Juan Gil Albert", 1990, p. 657-685.

28 Carta de Encarnación Gálvez de Arce, "librepensadora", a Rosario de Acuña, en Las Dominicales del Libre Pensamiento. Madrid, 7 de junio de 1885, p. 4 (Biblioteca Nacional, Madrid).

29 En muchos de esos arrabales abundaban los mestizos chinos.

30 [Extracto oficial de los avisos dados por la policía secreta de Manila al gobernador Ramón Blanco. Aviso del 25 de mayo de 1896], en La Política de España en Filipinas..., 1897, p. 89. La policía especial gubernativa, conocida como "Cuerpo de Vigilancia de Manila", fue creada por el gobernador civil Domínguez Alfonso para perseguir a las sociedades secretas (CASTILLO Y JIMÉNEZ, 1897: 382). 
la prensa conservadora pretendió minimizar la influencia de estos núcleos revolucionarios, proclamando en un artículo: ¿Qué significan cuarenta o cincuenta maestros ${ }^{31}$ (acaso no lleguen a ese número) que hayan seguido la bandera de la obcecación y la infidencia? ${ }^{32}$. Sin embargo, una vez sofocada la insurrección de 1896, se alzaron voces para reclamar que las Escuelas Normales de Maestros se pusiesen bajo la dirección de personas idóneas, para que en ellas se alejen todos los peligros de que se tornen en centros propagadores de doctrinas inconvenientes para la Religión y la Patria ${ }^{33}$.

A la vez que la mujer indígena participó en el movimiento de 1896, adhiriéndose a la sociedad Katipunan, las mestizas alcanzaron su protagonismo en las logias que le prestaron su apoyo y cobertura. Fueron las masonas de las familias ilustradas las que, por su mayor instrucción y lazos de parentesco con las principales figuras del movimiento nacionalista, se adhirieron tempranamente a las logias, animando a otras mujeres a adherirse a la masonería. Por lo demás, el sector mestizo ilustrado contaba con los instrumentos necesarios para iniciar esta lucha, ya que por su entidad formaba otra sociedad, racialmente indígena, pero por su cultura y sus modos de vida, europea ${ }^{34}$.

\section{LAS LOGIAS DE ADOPCIÓN}

La masonería de adopción (o logias de señoras) tuvo su origen en Francia en el siglo XVIII. La primera logia de este tipo (rito escocés) se fundó en París en 1775 con el nombre de Candor, participando en ella mujeres de la alta aristocracia. En un principio estas logias mantuvieron los ritos de la masonería simbólica, estableciendo los tres primeros grados: aprendiza, compañera y maestra, incorporando en otra etapa los restantes hasta el grado 10, que correspondía a la Princesa de la Corona, Soberana Masona (Morales Ruiz, 1990).

El auge de las ideas librepensadoras en la Península, en el último cuarto del siglo XIX, impulsó a muchas mujeres a solicitar su ingreso en la masonería, en cuyo seno obtendrían importantes conquistas. Incluso dentro de las logias masculinas del GOE se admitió la participación femenina, abriendo paso a la formación de cámaras de adopción ${ }^{35}$-sujetas a la supervisión de los Talleres-, con la condición de reunir un número mínimo de siete miembros. El GONE también contó entre sus filas a mujeres que habían demandado su incorporación en este Oriente, convencidas de que la masonería sería el redentor de nuestro sexo. El Gran Consejo General Ibérico fue mucho más lejos, y apostó por una participación igualitaria de la mujer en las logias, juzgando que la "adopción” era sólo aplicable a menores o ancianos (Morales Ruiz, 1990: 663-664). Ciertamente, dicho término parecía implicar la minoridad de la mujer, además de indicar su carácter de apéndice de las organizaciones masculinas.

Los avances de la masonería en la metrópoli, en términos de apertura hacia las mujeres, fueron cruciales para su evolución en el Archipiélago, no sólo en virtud de las relaciones mantenidas

\footnotetext{
Suponemos que en el uso del masculino genérico están comprendidos tanto hombres como mujeres.

["La instrucción pública”, de 2 de septiembre de 1897], en La Situación del País (Colección de artículos...), 1897, p. 145. Ídem.

34 PÉREZ LÓPEZ, Pablo, "Masonería e Insurrección en Filipinas en la publicista de la época (1896-1900)", en Masonería Española y América (Ferrer Benimeli, Comp.), Zaragoza, tomo II (1993), p. 855-876.

35 FERRER BENIMELI, José A., Masonería española contemporánea. Desde 1868 hasta nuestros días, Madrid, Siglo XXI Ed., 1980, tomo II, p.18-19. Este autor destaca la iniciación de mujeres en el rito masculino y su asistencia a los trabajos de las logias como una práctica propia del GOE, con el objeto de favorecer la formación de logias o cámaras de adopción; tal costumbre iba en contra de las Constituciones de Anderson, a pesar de consagrar éstas en sus bases los principios de igualdad, fraternidad y libertad.
} 
por los filipinos allí residentes con las logias peninsulares, sino también por la comunicación establecida entre las masonas de la Península y sus compañeras de las colonias de Ultramar (Morales Ruiz, 1990: 664). En lo relativo a las logias o cámaras de adopción en Filipinas, éstas se instalaron con posterioridad a la creación de Katipunan, con el objeto de brindar cobertura a sus planes revolucionarios.

El parentesco de las mujeres con algún integrante de las sociedades secretas, favoreció su ingreso a la masonería así como a la rama femenina de la sociedad revolucionaria Katipunan, pudiéndose destacar los casos de Rosario Villarruel y Marina Dizón como paradigmas de la acción insurreccional de las filipinas, sin desmedro, claro está, de otras figuras importantes en la lucha independentista. El padre de Rosario, Faustino Villarruel ${ }^{36}$, era un rico comerciante mestizo, integrante de la Liga Filipina y de Katipunan, así como gran impulsor de las logias masónicas en el país (Castillo y Jiménez, 1897: 376). Su propia vivienda había servido incluso como sede de numerosas tenidas y fundación de nuevas logias, entre ellas la denominada Walana (Sastrón 1901: 42-43), que organizó un Triángulo en Hong Kong, presidido por su hija Rosario. Marina Dizón ${ }^{37}$, por su parte, había crecido en un ambiente propicio para el cultivo de los ideales separatistas, ya que era hija de José Dizón, que habría de convertirse en uno de los trece mártires de Cavite (donde fue ajusticiado tras conocerse su implicación en la revolución de 1896) y esposa de José Suriano Santiago, una figura importante dentro del separatismo filipino.

El Triángulo Vanguardia, cámara de adopción de la logia Walana de Binondo ${ }^{38}$ (Ortiz de Andrés, 1993: 305), fue el ámbito donde algunas filipinas pertenecientes a familias de la minoría ilustrada nacionalista se iniciaron en la masonería inglesa y desarrollaron su labor conspirativa. Ante la falta de datos precisos, colegimos que su creación se habría producido entre 1891 y 1892, después de fundada en Filipinas la logia madre Nilad y tras ésta, otras muchas sociedades masónicas, entre ellas Walana. Además de Rosario Villarruel, formaron el Triángulo Vanguardia Valeriana Legazpi, Romualda Lanuza, Sixta Fajardo y Josefa Rizal, según los datos aportados por Ortiz de Andrés (1993: 306). Es probable que ese triángulo funcionase hasta que se organizó Katipunan (julio 1892) o poco tiempo más, ya que en 1893, algunas de sus integrantes se hallaban ya en Manila, organizando otras logias (Rosario Villarruel) o como miembros de la Katipunan (Marina Dizón).

Los masones mestizos fueron objeto de duros ataques, tanto por su prédica en contra del dominio español como por haber contaminado con su ponzoña a los nativos, como antes lo hiciera con las mujeres de su propio estrato étnico-social; sobre aquéllos cayó el reproche de haber halagado la fantasía de esa juventud inocente y candorosa (muchas masonas habían ingresado a la masonería con apenas 18 años, como Rosario Villarruel) en el satánico empeño de crear una logia femenina (Castillo y Jiménez, 1897: 17-18). Sin duda estas acusaciones iban dirigidas a hombres como Faustino Villarruel, Andrés Bonifacio o Emilio Jacinto, principales

36 F. Villarruel, también fundador de la logia Patria (1896), había obtenido del GOE el grado de Venerable (Castillo y Jiménez, 1897: 376). Tras la revolución de 1896, esta logia fue procesada por sus actividades antipatrióticas, al igual que las autoridades del GOE. Este hecho ponía en peligro la propia actividad masónica de este Oriente por cuanto se había autorizado la fundación de la logia Patria en un momento en que se hallaban prohibidas las actividades masónicas en el Archipiélago (HERNÁNDEZ SÁNCHEZ, Galo, “Opinión pública y masonería a través del Diario de la Guerra de Filipinas. Agosto 1896-julio 1897”, en Masonería Española y América, J. Ferrer Benimeli, J. Coord., Zaragoza, 1993, p. 824-825).

37 La biografía de M. Dizón y de otras revolucionarias, puede consultarse en QUINDOZA SANTIAGO, Lilia, Tales of Courage and Compassion. Stories of Women in the Philippine Revolution, Dwata Foundation and Hasik Inc., with Canadian Int. Development Agency, [Philippines], 1997. Esta autora incluye otras biografías de mujeres revolucionarias, como por ejemplo la de Teresa Magbanua, la "Juana de Arco" de Visayas. Las referencias a este libro han sido extraídas de la pág. Web http:www.salidumay.org (Online Resources and Advocacy Website for Gender and Development).

38 Barrio o arrabal de Manila, en el que se congregaba la población china y la mestiza china filipina. 
jefes katipuneros, responsables de haber corrompido a sus esposas e hijas al propiciar su ingreso en las sociedades secretas.

\section{MASONAS Y REVOLUCIONARIAS. ROSARIO VILLARRUEL Y MARINA DIZÓN: LA LOGIA SEMILLA Y LA SOCIEDAD KATIPUNAN}

Aunque sobre Charito Villarruel las fuentes documentales ofrecen mayores datos, resulta difícil seguir su trayectoria y conocer mayores detalles sobre su formación masónica y la labor militante desplegada entre las mujeres de su entorno. Cuando en los testimonios de la época se cita a esta revolucionaria filipina, generalmente es con el afán de presentarla como la demoníaca invención de su padre, que no dudó en sacrificarla a sus intereses. Huérfana de madre desde 1894, la joven Rosario había tenido una educación conventual como todas las muchachas de su tiempo y condición, haciendo gala de una auténtica devoción, lo que se resaltaba como contraste a sus ocupaciones posteriores, tras haber sido extraviada por el mamarracho de D. Faustino $^{39}$. Los datos biográficos proporcionados por la prensa conservadora y los escritos combativos de la masonería, están teñidos de cierto desdén masculino o bien se reducen a destacar sus cualidades físicas, presentándola como una muchacha mestiza, muy joven y muy bonita, a quien no se le perdonaban sus ojos filibusteros y sus afanes revolucionarios en una etapa de su vida que debióse haber pasado oyendo y diciendo amores [sic] honestos a los gustadores que la cortejaban ${ }^{40}$. Al hablar de los rasgos de su carácter y de su pertenencia a la masonería, se la tildaba de joven vivaracha y experta y aun de traviesa (adjetivo utilizado comúnmente para aludir a los "mesticillos" ilustrados que estudiaron fuera del país y lucharon por las reformas para Filipinas), reduciendo su militancia político-revolucionaria a una especie de capricho infantil. Por lo demás, algunas pinceladas sobre su vida privada apuntan a una supuesta liviandad de costumbres, un vil recurso sin duda utilizado para hundir su reputación, en virtud de su condición de masona; así por ejemplo, Reverter Delmás (1899) describía a Charito como una joven bastante agraciada y de la que se contaban aventuras que no se compaginaban muy bien con el odio que, ocultamente y en aquellos últimos tiempos, demostraba a los castilas ${ }^{41}$ (pág. 432). Es posible que se contabilizara entre esas aventuras al hombre con quien Rosario mantuvo una relación amorosa, el joven español filipino Luis Carvajal ${ }^{42}$, que acabó siendo deportado a Joló tras los sucesos de 1896.

Además de intervenir en la masonería en Hong Kong, Charito realizó desde esta ciudad un viaje al Japón, acompañando a su padre y a otros líderes nacionalistas, con el fin de conseguir apoyo para la guerra contra España (Castillo y Jiménez, 1897: 250). Su actuación revolucionaria continuó en Manila, donde fundó en 1893 la sociedad secreta Semilla, de la que fue Venerable Gran Maestra. Surgió así la primera cámara de adopción filipina, dependiente de la logia Walana, de la que también fueron sus componentes las hermanas Carlota Zamora, María Teresa Bordas, Fabiana Robledo (esposa de Sixto Celis, Venerable de la logia Dalisay), Lorenza Nepomuceno, Angélica López, Narcisa Rizal (hermana de José Rizal) y Marina Dizón, figurando dos hombres como "socios": el militar retirado Juan Duarte y el maestro Pedro Serrano ${ }^{43}$

\footnotetext{
Heraldo de Madrid. Madrid, 7 de enero de 1897, p. 1 (Biblioteca Nacional, Madrid).

Ídem.

Término con el que se designaba a los españoles peninsulares en Filipinas.

Castillo y Jiménez (1897: 386-387) sostiene que este joven español había sido incluido por el padre de Rosario Villarruel en la lista de componentes de la logia Patria para disimular su "anti-españolismo".

43 Pedro Serrano había formado parte de una logia de peninsulares en España, fundando a su regreso Nilad, la primera logia filipina (Retana 1897, III, p. 270).
} 
(Retana 1897, III: 183). Las masonas filipinas fueron calificadas como mujeres de escasa o de ninguna instrucción aunque aparentando tener alguna enseñanza que, mejor empleada, hubiera hecho de ellas excelentes madres de familia (Castillo y Jiménez, 1897: 18-19). Esa falta de preparación resulta poco fácil de creer, atento a los lazos que unían a Rosario, las hermanas de Rizal y a sus compañeras de logia en Hong Kong con destacados separatistas filipinos.

Después de organizar la logia Semilla, Charito continuó con su campaña proselitista, para reclutar adeptas entre las jóvenes mestizas del círculo ilustrado, a juzgar por los avisos de la policía de mayo de 1896 -cuando ya la actividad masónica era un secreto a voces-, informando que se agita mucho y hace propaganda entre las jóvenes de su clase $e^{44}$. Las logias Walana, Nilad, Modestia, Dalisay y Taliba, mantuvieron una estrecha colaboración con la sociedad Katipunan, según las declaraciones tomadas a los implicados en el levantamiento de 1896 (Retana 1897, III: 329), lo que confirma la función de la logia Semilla y de otras cámaras de adopción como encubridoras de las actividades katipuneras. Las logias también contaban con agentes de ambos sexos, que cumplían con las tareas de espionaje, aunque sin pertenecer a la masonería ${ }^{45}$.

Rosario tuvo una activa participación en los preparativos de la insurrección, según los informes de la policía secreta de Manila, que a lo largo de 1895 y 1896 mantuvo una celosa vigilancia sobre las reuniones masónicas que la joven presidía en Manila y pueblos cercanos; verdaderos focos filibusteros en los que se pronunciaban encendidos discursos, con gritos y vivas subversivos ${ }^{46}$. Al descubrirse a los principales jefes de Katipunan y a los masones que preparaban la revolución, Rosario Villarruel fue detenida y encerrada en un convento -el colegio Santa Rosa-, pasando a disposición de los tribunales militares. Su arresto fue decisivo para el enjuiciamiento de muchos líderes separatistas -practicado de modo simultáneo a la acción militar contra los insurrectos-, al haberse encontrado en su domicilio abundante documentación en clave secreta (Retana 1897, III, 377).

Finalmente, Rosario pudo salvarse de la ejecución tras la solicitud de indulto presentada por una comisión de Venerables un mes después del fusilamiento de su padre ${ }^{47}$ (ocurrido en enero de 1897); también fueron indultadas Trinidad y Josefa Rizal, hermanas de José Rizal (ajusticiado en 1896 en el campo de Bagumbayan) y el padre de éste ${ }^{48}$. Otras fuentes incluyen a Charito Villarruel en una lista de 300 deportados a la isla de Paragua, que habían sido conducidos hacia este destino en un "transporte de guerra", en septiembre de 1896 (Reverter Delmás, 1899: 432). Otras muchas mujeres fueron arrestadas y luego deportadas (Castillo y Jiménez, 1897: 129), incluso a prisiones militares de España (Reverter Delmás 1899: 677).

Conforme a las declaraciones tomadas en 1896 a los detenidos por su implicación en la insurrección, se desveló la existencia de una Katipunan de mujeres, cuya presidencia estuvo a cargo de Marina Dizón (Retana 1897, III: 377), también integrante de la logia Semilla. En el ingreso a la sociedad revolucionaria había sido fundamental la intermediación de su primo, Emilio Jacinto, encargado del reclutamiento de mujeres, junto con el jefe supremo de la organización, Andrés Bonifacio ${ }^{49}$ (Quindoza Santiago, 1997). Si bien Katipunan no era una logia masónica, tenía en común con ellas su carácter secreto, su modelo organizativo y los ritos de iniciación, que en el caso de la sección femenina estuvieron a cargo de Marina Dizón.

\footnotetext{
[Aviso dado el 25 de mayo de 1896], en La Política de España en Filipinas..., 1897, p. 89.

Aviso del 3 de junio de 1897], ibid., p. 126.

[Aviso del 7 de mayo de 1896], ibid., p. 88.

[Noticia enviada desde Manila en 28 de febrero de 1897], ibid., p. 91.

"La masonería" (15 de mayo de 1897), ibid., p. 227.

La esposa de Bonifacio, Gregoria de Jesús, también se convirtió en una de las figuras destacadas de la revolución filipina (Quindoza Santiago, 1997).
} 
Marina fue una mujer con estudios y gran afición a la historia y a la geografía, destacándose también por sus virtudes musicales, que la llevaron a participar en la orquesta de Trozo (su barrio natal, en Manila), actuando como cantante y violinista (Quindoza Santiago 1997). Como en la masonería, la mayoría de las mujeres katipuneras tenía un parentesco cercano con un miembro de la organización; practicaban entre ellas el socorro mutuo, además de tener asignada la tarea de organizar reuniones y bailes en las casas donde se celebraban las sesiones secretas, manteniéndolas a buen recaudo de los cuerpos de vigilancia (Retana 1897, III: 377-378).

A raíz de los operativos policiales puestos en marcha en agosto de 1896, para perseguir a los insurrectos, Marina Dizón huyó de Manila con su esposo. No tardó en ser arrestada por la policía en una estación de ferrocarril, siéndole incautada la documentación que llevaba consigo, relacionada con las actividades de Katipunan. Fue puesta en libertad al poco tiempo, aunque permaneció sometida a una rígida vigilancia mientras duró su periplo por varias provincias del Archipiélago (Quindoza Santiago, 1997).

A pesar de que las autoridades coloniales lograron controlar el estallido de la sublevación en Manila, el germen revolucionario sembrado por los mestizos se había propagado, contagiando a las mujeres de otros estratos étnicos; para algunos, la revolución de 1896, movimiento de rebeldía contra la madre patria, había sido una conspiración pacientemente trabajada y de la cual formaban parte mujeres del pueblo y la buena sociedad (Reverter Delmás 1899: 473). Muchas mujeres de los barrios y de pueblos aledaños se trasladaron a la capital, donde se volcaron a la acción clandestina, conforme a las investigaciones realizadas por la policía secreta que vigilaba el orden público. Mientras los hombres de los suburbios inmediatos a Manila se lanzaron a combatir en los campos, comenzando así la rebelión armada, las revolucionarias filipinas desplegaron su campaña propagandista en apoyo a los combatientes, sin ocultar su gran odio a los españoles (Reverter Delmás 1899: 39). En esta movilización femenina, que se extendió también a las provincias, se destacó la presencia de viudas -que organizaban reuniones secretas en sus casas o bien arengaban a los insurrectos, como la viuda de Rizal en Cavite ${ }^{50}$ - y de mujeres de bastante edad, que repartían impresos contra España y a favor de la independencia de Filipinas y Cuba ${ }^{51}$

La dura represión desatada al descubrirse las actividades revolucionarias y constatarse la participación femenina en las logias y en la sociedad Katipunan, había dado lugar a no pocas retractaciones de esas engañadas y aun fanatizadas indias ${ }^{52}$. A pesar de que algunos peninsulares consideraban que el indígena había sido embaucado por los revolucionarios, viéndolo como el buen salvaje que se deja seducir por el mestizo de chino y en general de toda la mesticería, y huye del español, que lo trata bien (Castillo y Jiménez 1897: 15), los términos de indio e india fueron utilizados como arma arrojadiza cuando así convenía, resumiendo en ellos el desprecio hacia los mestizos.

Como consecuencia de la sublevación iniciada en 1896, las todopoderosas órdenes religiosas instaladas en la colonia desde sus inicios, vieron quebrarse su papel hegemónico y el respeto absoluto que otrora le prodigara la población nativa. No era casual que un agustino -congregación pionera en la evangelización de la antigua colonia española en Oriente-, autor de varios artículos sobre la masonería en Filipinas, se sumase al coro de voces que condenaba a las logias femeninas, cuyas perversas conductoras habían logrado, valiéndose de los buenos sentimientos de las indias, llevarlas por la senda contraria a la fe y a la lealtad a la madre patria; en suma, para hacerles perder la fe cristiana y el amor a España ${ }^{\mathbf{5 3}}$.

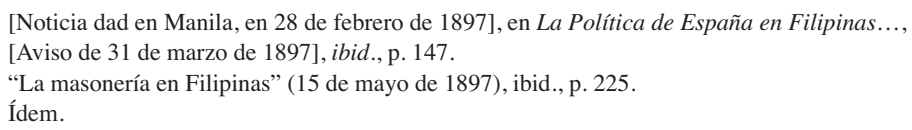

